\title{
Fate of selected drugs in the wastewater treatment plants (WWTPs) for domestic sewage
}

\author{
Agostina Chiavola $^{1} \cdot$ Pierpaolo Tedesco $^{1} \cdot$ Maria Rosaria Boni $^{1}$
}

Received: 30 December 2016/Accepted: 18 May 2017

(C) Springer-Verlag Berlin Heidelberg 2017

\begin{abstract}
The wide diffusion of Emerging Organic Micropollutants (EOMs) in the environment is receiving increasing attention due to their potential toxicological effects on living organisms. So far, the Wastewater Treatment Plants (WWTPs) have not been designed with the purpose to remove these contaminants; therefore, they can represent the major source of release into the environment both through the effluent and the wasted sludge. The fate of EOMs in the WWTPs is still not completely known; further investigations are therefore needed to assess if it is possible to exploit the existing treatment units to reduce EOM concentrations or which processes must be implemented to this purpose. Among the wide class of EOMs, the present study focused on the following drugs of abuse: amphetamine (AM), methamphetamine (MET), 11-nor- $\triangle 9$-THC9 carboxy (THC-COOH) and benzoylecgonine (BEG). Presence and removal efficiency of these drugs in the activated sludge tank of a WWTP for domestic sewage was investigated through analyses at both full-scale and laboratory scale. Determinations conducted in the full-scale WWTP highlighted that, among the searched drugs, AM was found to be the most abundant in the influent and effluent of the biological oxidation tank, while 11-nor- $\Delta$ 9-THC-9carboxy was present at the lowest concentration. Some removal took place in the units prior to the oxidation tank, although the main reduction was observed to occur in the biological oxidation reactor. All the drugs showed a wide variability of the measured concentrations during the
\end{abstract}

Responsible editor: Ester Heath

Agostina Chiavola

agostina.chiavola@uniroma1.it

1 Department of Civil, Building and Environmental Engineering, Faculty of Civil and Industrial Engineering, Sapienza University of Rome, Via Eudossiana 18, 00184 Rome, Italy week and the day. Taking into account results from both fullscale observations and batch tests, removals in the biological reactor were found within the following ranges: $33-84 \%$ for AM, 33-97\% for MET, 33-57\% for BEG and $29-83 \%$ for THC-COOH. These removals were due to a combination of adsorption and biodegradation mainly, while volatilization did not play a significant role. Other processes, e.g. hydrolysis, were likely to occur.

Keywords Biodegradation $\cdot$ Emerging organic micropollutants $\cdot$ Illicit drugs $\cdot$ Wastewater treatment plants

\section{Introduction}

The term "emerging pollutants" refers to chemical or microbial constituents which have been in the environment for a long time, but only recently the analytical techniques reached the ability to detect their trace levels. Furthermore, advances in ecotoxicology demonstrated their tendency to be persistent and bioaccumulate in the environment with possible negative impacts on the ecosystem (Díaz-Cruz et al. 2009).

Among the emerging pollutants, illicit drugs are one of the latest groups that have been identified in the aquatic environment (Kasprzyk-Hordern et al. 2010). They include either plant-derived or synthetic pharmaceutical compounds for which nonmedical use is prohibited by national or international laws (Daughton 2011). Illicit drugs fall into the categories of opioids, cocaine, cannabis, amphetamine-type substances (ATSs), ecstasy-group substances and New Psychoactive Substances (Hall et al. 2008).

The current state of knowledge on their occurrence, transportation, distribution and transformation in water bodies and ambient air is still incomplete. It is known that, after legal or illegal consumption, drugs and their metabolites are excreted 
in urine, faeces, saliva or sweat (Bodík et al. 2016). Then, they enter sewage network through which are transferred to the wastewater treatment plants (WWTPs). Another source of release is through direct disposal of clandestine laboratory wastes into sewage (Boles and Wells 2010).

In the WWTPs, drugs and their metabolites may undergo a series of processes, such as volatilization, adsorption, biodegradation, depending on their chemical-physical properties and the specific wastewater characteristics (e.g. temperature, $\mathrm{pH}$, redox environment), operating parameters (e.g. sludge retention time, hydraulic retention time) and treatment technologies (Kasprzyk-Hordern et al. 2009; Evgenidou et al. 2015).

In most cases, biological treatment processes in the WWTPs are unable to sufficiently reduce the load of these compounds in the wastewater. For instance, drugs, as other EOMs, are usually only partially biodegraded and their metabolites are still found in the plant effluent (Loos et al. 2013). They can also be transferred by adsorption onto sewage sludge solids with low or no degradation. Consequently, drugs and/or their metabolites enter the environment through either effluent discharge into the receiving water body or excess sludge disposal (Kaleta et al. 2006; Boles and Wells 2010). Although their environmental concentrations are not very high, ecotoxicological effects can be generated due to accumulation and/or slow biodegradation, which potentially impact human health and ecosystem functioning through chronic low level exposure (Pal et al. 2013). Furthermore, the effects can be modified or enhanced by the presence of mixtures of different EOMs (Pomati et al. 2008). Due to the uncertainties in the current knowledge on their concentrations, frequency and distribution in water bodies (Daughton 2011), no guidelines have been so far fixed about their maximum permissible concentrations in surface water (Pal et al. 2013). In the last few years, increasing concern about their effects on human beings and environment fostered studies to better understand distribution, presence and fate of drugs in wastewater. However, although WWTPs are deemed as one of the main sources of release into the environment, researches on contribution of different treatment units on drug removal are still very few (Evgenidou et al. 2015). Such information would represent a prerequisite to identify and foster safe and appropriate control measures to reduce the load released by the WWTPs into the environment, with the aim to limit the potential hazard to human and ecological health.

The present study belongs to a wide research activity focusing on the fate of some emerging organic micropollutants through WWTPs for domestic sewage. A previous study investigated the removal of endocrine disrupters (Chiavola et al. 2016), while the present paper shows the results regarding selected drugs, i.e. amphetamine (AM), methamphetamine (MET), 11-nor- $\triangle$ 9-THC-9carboxy (THC-COOH) and benzoylecgonine (BEG). AM is a potent central nervous system stimulant, used to treat narcolepsy, obesity and depression. AM group compounds are primarily excreted unmetabolised (Boles and Wells 2010), but excretion rate can change with $\mathrm{pH}$ of urine of that particular user, route of intake and dose (van Nuijs et al. 2011). MET is a potent central nervous system stimulant, used as a recreational drug and less commonly as a treatment for attention deficit disorder and obesity. BEG has been selected since it is considered the main metabolite of cocaine reported in urine, along with ecgonine methyl ester, both excreted at higher concentration than cocaine (Chiaia et al. 2008; van Nujis et al. 2009a, b). It can be found in the urine for considerably longer than cocaine itself. THC-COOH is the main secondary metabolite of tetrahydrocannabinol (THC) which is formed in the body after cannabis is consumed (Evgenidou et al. 2015).

The experimental activity of the present study included two phases: (1) the first one, carried out at full-scale, aimed at investigating the presence of the selected drugs in the influent and effluent of a WWTP, and in the influent to the biological reactor; (2) the second phase, conducted at lab-scale, aimed at determining contribution of the main processes occurring in the biological oxidation tank of a WWTP (i.e. volatilization, adsorption and biodegradation) to the overall removal observed in the full-scale plant. The aim of the study was to obtain a better understanding of how a WWTP with a traditional layout can affect distribution and load of these drugs in the environment.

\section{Materials and methods}

\section{Full-scale experimental activity plan}

The WWTP is located in the Center Italy and receives and treats a domestic sewage (Chiavola et al. 2016). Plant layout includes the main following units: storage tank, pumping station, coarse screen, grit-grease removal, aerobic biological reactor $\left(56 \mathrm{~m}^{3} / \mathrm{h}\right.$ as average influent flow rate; $50 \mathrm{~m}^{3} / \mathrm{h}$ as average recycle flow rate from the secondary settlement tank to the biological reactor; $8.11 \mathrm{~h}$ as design Hydraulic Retention Time at average flow rate, HRT; 8 days as average Sludge Retention Time, SRT; $3000 \mathrm{mg}$ MLSS/L as average activated sludge concentration, $\mathrm{X}$, in the biological reactor), secondary settler and disinfection. Layout of the plant is shown in Fig. 1.

Sludge treatment consists of aerobic digestion, thickening and drying by belt-filter press. The presence of drugs in the WWTP was assessed by measuring their concentration at the points indicated in Fig. 1, which correspond to the following stages: influent to the plant; influent and effluent of the biological oxidation tank; and sludge recycle loop. Samples at the influent of the plant and of the biological reactor and from the sludge recycle loop stages were collected manually, whereas samples of the biological reactor effluent were provided by an auto-sampler (Sigma 900, supplied by Mach). All the samples were instantaneous. Along with the selected drugs, the 


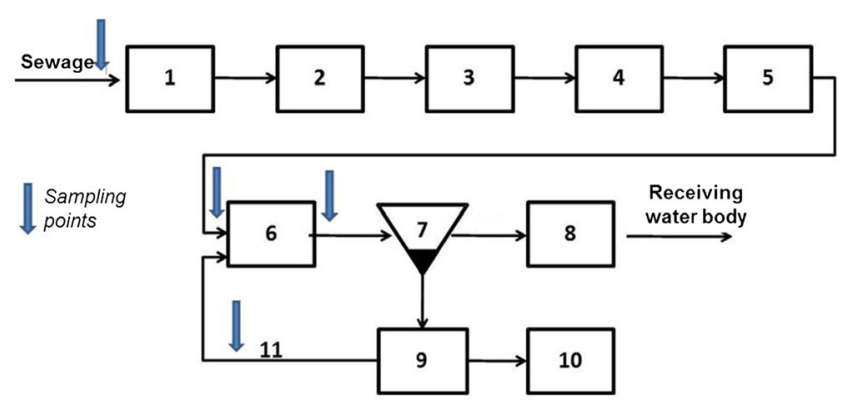

1) Storage tank;

5) Degreasing;

2) Pumping station; 6) Activated sludge tank;

3) Screening;

4) Degritting

7) Secondary se

9) Sludge storage

10) Sludge treatment

Fig. 1 Layout of the WWTP and sampling points

following main parameters representing plant operation were also monitored: $\mathrm{COD}, \mathrm{BOD}_{5}$, TSS, ammonia nitrogen, nitric and nitrous nitrogen and $\mathrm{pH}$. This monitoring allowed to confirm that plant operation was at pseudo-steady state conditions during the drug sampling campaign.

Samples were always collected at hourly interval and using glass containers. After collection, they were stored at $4{ }^{\circ} \mathrm{C}$ until the analyses.

The influent and effluent samples of the biological reactor were collected based on the real value of the hydraulic residence time that was previously experimentally determined. To this purpose, tests using $\mathrm{Li}_{2} \mathrm{CO}_{2}$ as a tracer were carried out following the procedure outlined by Collivignarelli et al. (1995). For instance, in the experimental phase, the tracer was injected into the inlet of the tanks in a pulse-mode; concentration in the outlet and recycle line were measured at prefixed time intervals. The experimental curve of the Retention Time Distribution (RTD) was then calculated by plotting the measured effluent concentration versus time. In the following phase, the biological reactor was modelled assuming its hydraulic pattern as a Continuous Flow Stirred Tank Reactor (CFSTR). The theoretical RTD curve was then determined. Comparison of the theoretical and experimental RTD curves allowed to calculate the Real Hydraulic Residence Time (rHRT).

\section{Batch tests}

Batch tests were carried out by following the procedure outlined in Chiavola et al. (2016). Particularly, a drug containing solution was mixed with an activated sludge sample collected at the biological oxidation tank of the WWTP described in the previous section. Sludge samples were withdrawn from the plant only few hours before the beginning of the batch tests and then stored at $4{ }^{\circ} \mathrm{C}$ until their use.

Each test was performed in a $600-\mathrm{mL}$ volume (V) glass Erlenmeyer flask, repeated in duplicate, and the results obtained were averaged. Each flask was placed on a magnetic stirrer so as to maintain the content under completely mixed conditions. The stirrer allowed also to maintain the temperature within the range $22 \pm 1^{\circ} \mathrm{C}$. The flask was covered with aluminium foils to avoid photo-degradation phenomena. The initial concentration of each drug within the flask was fixed at $1000 \mathrm{ng} / \mathrm{L}$ : this value was chosen to replicate roughly the lowest value found in the WWTP. The same concentration was used for all the investigated drugs for sake of simplicity. The initial biomass concentration was $3000 \mathrm{mg} /$ L MLSS as in the biological reactor. During the test, drug concentration inside the flasks was measured at fixed time intervals, with the aim to determine the kinetics of the removal process. To this purpose, each test was repeated for different durations under the same operating conditions, using one flask for each contact time: 1/2, 1, 4, 8, 24 and 48 h. pH, dissolved oxygen concentration (DO) and temperature values were recorded at regular time intervals using standard probes. Nitrification and COD removal were always monitored, by sampling the content and analysing the following parameters at different times: $\mathrm{COD}, \mathrm{NH}_{3}-\mathrm{N}$, $\mathrm{NO}_{2}{ }^{-}-\mathrm{N}$ and $\mathrm{NO}_{3}{ }^{-}-\mathrm{N}$ concentrations. Furthermore, concentrations of MLSS and MLVSS were determined at the beginning and at the end of each contact time in Experiments 2 and 3: since at this time the test was stopped and the content analysed, it was possible to measure also solid concentration within each flask.

For each of the selected drugs, three series of batch test (namely Experiment 1, Experiment 2 and Experiment 3) were fulfilled. The series differed based on the type of mixed solution used in the batch, with the aim to evaluate contribution of each of the following processes to drug removal: (1) volatilization; (2) adsorption onto the sludge flocs and (3) biodegradation. Details of each series are reported below.

\section{Experiment 1-blank test}

Each flask was filled with only drug solution and maintained in operation under mixed conditions for each contact time as indicated previously. At the end of each contact time, the residual drug concentration in the liquid phase was measured and the possible removal calculated.

\section{Experiment 2-inhibited activated sludge}

This test was performed with the aim to evaluate only adsorption of drugs onto sludge solids. To this purpose, the test was carried out using inactivated sludge, mixed with drugs and nutrient solutions. Inactivation was carried out on sludge samples (collected as previously described) according to Taewoo and Willie (2007): the procedure requires addition of sodium azide and monitoring DO concentration inside the flask with time. Sludge inactivation was considered successful if DO 
value never decreased. A nutrient solution was added to simulate the same conditions as in Experiment 3.

\section{Experiment 3-activated sludge}

This test was carried out with the aim to investigate drug removal due to biological processes. A sample of activated sludge from the WWTP was added to the flask $(3000 \mathrm{mg} / \mathrm{L}$ MLSS as initial concentration). To sustain the microbial metabolism, beside the drug solution, the flask was also provided with $300 \mathrm{mg} / \mathrm{L} \mathrm{COD,} 80 \mathrm{mg} / \mathrm{L} \mathrm{NH}_{3}-\mathrm{N}$ and $25 \mathrm{mg} / \mathrm{L} \mathrm{P}$ (as initial concentrations inside the flask) and micronutrients (through the addition of tap water).

\section{Kinetic models}

The experimental data collected from Experiment 3 were fitted by the following kinetic models: zero, first, pseudo-first, second and pseudo-second order. The best fitting model was considered that one providing the higher value of the correlation coefficient, $R^{2}$, between experimental and modelled data using the linear form of each equation, as reported below (Chiavola et al. 2016).

- Zero-order

$$
C(t)=C_{\mathrm{IN}}-K_{0} \cdot t
$$

- First-order

$$
\ln C(t)=\ln C_{\mathrm{IN}}-K_{1} \cdot t
$$

- Second-order

$$
\frac{1}{C(t)}=\frac{1}{C_{\mathrm{IN}}}-K_{2}+t
$$

- Pseudo-first order

$$
\ln \left(q_{\mathrm{e}}-q(t)\right)=\ln q_{\mathrm{e}}-K_{1}^{\prime} \cdot t
$$

- Pseudo-second order

$$
\frac{1}{q(t)}=\frac{1}{K_{2}^{\prime} \cdot q_{\mathrm{e}}^{2}}+\frac{1}{q_{\mathrm{e}}} \cdot t
$$

where $C_{\mathrm{IN}}$ and $C(t)$ indicate drug concentrations in the liquid phase at the beginning and at any time $t$ during the test, respectively; $K_{0}, K_{1}, K_{2}, K_{1}^{\prime}$ and $K_{2}^{\prime}$ represent rate constants of zero, first, second, pseudo-first and pseudo-second order models, respectively; $q_{\mathrm{e}}$ and $q(t)$ stand for the amount of drugs per unit mass of adsorbent (i.e. sludge solids) at the end of the test (i.e. at $48 \mathrm{~h}$ ) and at any time $t$, respectively. The values of the kinetic constants were calculated based on the amount of drugs removed from the liquid phase during Experiment 3. The following equations were used to this purpose:

$q_{\mathrm{e}}=\frac{\mathrm{M}_{\mathrm{ads}}(e)}{\operatorname{MLSS}}=\frac{\left(C_{\mathrm{IN}}-C_{\mathrm{e}}\right)}{\operatorname{MLSS}}$

$q(t)=\frac{\mathrm{M}_{\mathrm{ads}}(t)}{\operatorname{MLSS}}=\frac{\left(C_{\mathrm{IN}}-C(t)\right)}{\operatorname{MLSS}}$

In Eqs. (6) and (7), $M_{\mathrm{ads}}(e)$ and $M_{\mathrm{ads}}(t)$ represent the mass of drug adsorbed on the sludge at $t=48 \mathrm{~h}$ and at any time $t$, respectively, during the tests. The term $C_{\mathrm{e}}$ represents drug concentration in the liquid phase at $t=48 \mathrm{~h}$. Measurements of solid concentration at the beginning and at the end of each contact time showed that microbial growth during the tests was negligible. Therefore, MLSS concentration in the calculation was always assumed equal to $3000 \mathrm{mg} / \mathrm{L}$.

\section{Analytical methods}

High-grade chemicals were used for preparing the solutions used in the batch experiments (Chemical Research 2000 and Sigma Aldrich). Table 1 lists main properties of the chemicals used in the experimental activities. Nutrient solutions added in Experiments 2 and 3 were made by dissolving into tap water proper amounts of $\mathrm{NH}_{4} \mathrm{Cl}$ and $\mathrm{NaH}_{2} \mathrm{PO}_{4} \cdot 2 \mathrm{H}_{2} \mathrm{O}$ to provide ammonia and phosphorous, respectively, and sodium glutamate to add COD. Micronutrients were supplied by using tap water. Drug solutions were made by adding proper amounts of chemicals into Milli-Q water.

For Experiments 2 and 3, samples collected from the tests were firstly filtered (1.2 $\mu \mathrm{m}$ MNGF-3 glass fibre) to remove suspended solids. APHA methods were used to determine concentrations of the following parameters: $\mathrm{COD}, \mathrm{NH}_{3}-\mathrm{N}$, $\mathrm{NO}_{2}{ }^{-}-\mathrm{N}, \mathrm{NO}_{3}{ }^{-}-\mathrm{N}$, MLSS and MLVSS (APHA, AWWA, WEF 2005). Drug concentrations were analytically determined through the following procedure. Extraction from the liquid phase was conducted according to Castiglioni et al. (2006), modified as reported by Saito et al. (2007). Samples were filtered using glass fibre filters MNGF-3 $1.2 \mu \mathrm{m}$ (Macherey-Nagel). Sodium azide was added to the filtrate in order to obtain a $\mathrm{pH}$ value of 8 , with the aim to prevent any change in the composition of the samples due to onset degradation phenomena. A total of $100 \mathrm{ng}$ of amphetamine-d6, $100 \mathrm{ng}$ of methamphetamine-d9, $100 \mathrm{ng}$ of 11nor- $\Delta$ 9-THC-9carboxy-d 3 and $100 \mathrm{ng}$ of benzoylecgonind3 were added as internal standards The liquid samples were subjected to Solid Phase Extraction (SPE) using Supel ${ }^{\mathrm{TM}}$ Select HLB SPE (200 mg, $6 \mathrm{~mL}$ ) cartridges and subsequent elution. The collected eluate was evaporated up to dryness under nitrogen bubbling. The dry residues were derivatized by adding $100 \mu \mathrm{L}$ ethyl acetate and $100 \mu \mathrm{L}$ MSTFA; derivatization process was completed by placing the vials in a 
Table 1 Main characteristics of the chemicals

\begin{tabular}{llllr}
\hline Chemical & Acronym & Formula & CAS number & EC number \\
\hline Cocaine & $\mathrm{CO}$ & $\mathrm{C}_{17} \mathrm{H}_{21} \mathrm{NO}_{4}$ & $50-36-2$ & $200-032-7$ \\
Amphetamine & $\mathrm{AM}$ & $\mathrm{C}_{9} \mathrm{H}_{13} \mathrm{~N}$ & $300-62-9$ & $205-850-8$ \\
Methamphetamine & $\mathrm{MET}$ & $\mathrm{C}_{10} \mathrm{H}_{15} \mathrm{~N}$ & $537-46-2$ & $208-668-7$ \\
$11-\mathrm{Nor}-\Delta 9-\mathrm{THC}-9$ carboxy & $\mathrm{THC}-\mathrm{COOH}$ & $\mathrm{C}_{21} \mathrm{H}_{28} \mathrm{O}_{4}$ & $56354-06-4$ & $200-659-6$ \\
Benzoylecgonine & $\mathrm{BEG}$ & $\mathrm{C}_{16} \mathrm{H}_{19} \mathrm{NO}_{4}$ & $519-09-5$ & $208-263-5$ \\
Sodium azide & $\mathrm{SA}$ & $\mathrm{NaN}_{3}$ & $26628-22-8$ & $247-852-1$ \\
\hline
\end{tabular}

thermostatic bath at $65 \pm 5^{\circ} \mathrm{C}$ for $60 \mathrm{~min}$. The derivatized solutions, brought back at room temperature, were analysed by using a gas chromatograph mass spectrometry HP 5973 (Agilent Technologies). Data were acquired in a full scan mode (from 40 to $500 \mathrm{~m} / \mathrm{Z}$ ) for quantitative analysis and in selected ion monitoring (SIM) mode for qualitative analysis. The data were found to be reproducible with a variability of about $\pm 10 \%$.

About statistical methods, measurements were repeated three times to assess repeatability. Derivatization was performed as outlined above. Calibration curves for each drug are reported below:

$$
\begin{aligned}
& \text { AM } \mathrm{y}=1.126 \mathrm{x}-0.5959\left(R^{2}=0.9732\right) \\
& \text { MET } \mathrm{y}=0.0694 \mathrm{x}+0.282\left(R^{2}=0.9426\right) \\
& \text { BEG } \mathrm{y}=0.192 \mathrm{x}+0.1808\left(R^{2}=0.9596\right) \\
& \text { THC-COOH } \mathrm{y}=0.2038 \times 0.0555\left(R^{2}=0.8984\right)
\end{aligned}
$$

Limit of detection (LOD) was considered for a signal/noise $(\mathrm{S} / \mathrm{N})$ ratio below 3 , while limit of quantification for $\mathrm{S} / N<10$. Control of the detection limit of the calibration curve had to provide no more than $10 \%$ error. Accuracy values were calculated by means of the Multiquant software.

\section{Calculation methods}

Removal percentage $R(\%)$ of drugs from the liquid phase at the end of each experiment was calculated by the following equation:

$$
R(\%)=\frac{C_{\mathrm{IN}}-C_{\mathrm{e}}}{C_{\mathrm{IN}}} \times 100
$$

In Experiment 1, the removal was assumed to be only due to volatilization (or chemical transformation), since microorganisms were not present and any other phenomenon was prevented. In Experiment 2, both volatilization and adsorption were likely to occur, while biodegradation was absent since activated sludge was maintained chemically inhibited. In Experiment 3, all the processes, i.e. volatilization, adsorption and biodegradation, were likely to take place. Specific contribution due to each of these processes depended on the type of drug and its properties.

Indicating with RV, RA and RB percentage removal due to either only volatilization, or adsorption or biodegradation, respectively, total removal in the three tests was assumed to be equal to:

$R(\%) 1=\mathrm{RV}$

$R(\%) 2=\mathrm{RV}+\mathrm{RA}$

$R(\%) 3=\mathrm{RV}+\mathrm{RA}+\mathrm{RB}$

where $R(\%) 1, R(\%) 2$ and $R(\%) 3$ stand for the total percentage removal measured in Experiment 1, 2 and 3, respectively.

It was assumed that the same removal percentage due only to volatilization (RV) was occurring in all the tests since the operating conditions were always the same. Therefore, it was possible to calculate RA as the difference between $R(\%) 2$ and the value of RV determined in Experiment 1.

Similarly, RB was calculated as the difference between $R(\%) 3$ and the values of RV and RA determined in the other experiments.

As far as the adsorption process taking place in Experiment 3 , it is likely that the drug was firstly adsorbed onto the sludge flocs and then eventually biodegraded. It was assumed that the mass adsorbed in Experiment 3 was the same as in Experiment 2 (Chiavola et al. 2016).

The adsorption process was also described by the following parameters (Clara et al. 2004):

- the specific adsorption coefficient, $K_{\mathrm{D}}$, defined as follows (12):

$$
K_{\mathrm{D}}=\frac{q_{\mathrm{e}}}{C_{\mathrm{e}}} \times 100
$$

- $K_{\mathrm{OM}}$, which relates the $K_{\mathrm{D}}$ value to the organic matter content of the adsorbent, defined as follows (13):

$$
K_{\mathrm{OM}}=K_{\mathrm{D}} \frac{\mathrm{MLSS}}{\mathrm{MLVSS}}
$$




\section{Results and discussion}

\section{Main chemical-physical properties of drugs}

The main chemical-physical properties of drugs were calculated with the aid of Estimation Programs Interface Suite (EPI Suite, USEPA 2011) and then compared with the experimental results. For instance, the following software were applied to determine the values of solubility $\left(\gamma_{\text {sat }}\right)$, Henry's constant $(H)$, organic carbon/water partitioning coefficient $\left(K_{\mathrm{OC}}\right)$ and nOctanol/water partition coefficient $\left(K_{\mathrm{OW}}\right)$, respectively: WATERNTTM, HENRYWINTM, KOCWINTM and KOWWINTM

The results obtained are listed in Table 2.

\section{Full-scale experimental activity}

Tracer tests, conducted as described in the "Materials and methods" section, allowed to determine the rHRT of the activated sludge tank which resulted to be equal to $8 \mathrm{~h}$. Sampling time of influent and effluent of the biological reactor was scheduled based on rHRT. Figure 2 shows the average concentrations measured at different times in each of the investigated stages of the WWTP. For instance, referring to AM, the first sampling time of Fig. 2, i.e. 9/17 on $\mathrm{x}$-axis, indicates that the influent to the plant (IN plant), the influent to the biological reactor (IN bio) and the sludge recycle line (Recycle) were sampled at 9:00 am, while the effluent from the biological reactor (OUT bio) at 17:00 (5 pm), i.e. after 8 h. Similarly, the other sampling times reported on $\mathrm{x}$-axis.

Concentrations lacking at any time in Fig. 2 are those that could not be determined with enough analytical reliability.

Analyses of the collected samples showed that all drugs were present in each of the investigated stages. Among them, $\mathrm{AM}$ was the most abundant while $\mathrm{THC}-\mathrm{COOH}$ was present at the lowest concentration. Maximum concentration in the influent to the plant of AM, MET, BEG and THC-COOH was found to be $58.6,6.8,4.8$ and $0.7 \mu \mathrm{g} / \mathrm{L}$, respectively. Values of $\mathrm{AM}$ and MET are significantly higher than those reported by other authors (e.g. Kasprzyk-Hordern et al. 2009; Postigo et al. 2010; Pal et al. 2013). Boles and Wells (2010) reviewed data on the presence of AM and MET in the influent and effluent of a number of WWTPs: concentrations in the influent were mostly of the order of several dozens of $n g / L$, with just few cases up to $700 \mathrm{ng} / \mathrm{L}$ or above. Castiglioni et al. (2006) refer AM and MET concentrations in the influent of the Nosedo plant at $14.7 \pm 10.6$ and $16.2 \pm 7.1 \mathrm{ng} / \mathrm{L}$, respectively.

The different values and the wide fluctuation observed in the present study are likely to be ascribed to the different consumption rates of the people contributing to the sewage in the catchment basin discharging to the investigated WWTP, and to the different types of sources which are either domestic or industrial. It is known that concentrations in the influent are strictly related to the drug use pattern in the local community, while those in the effluent reflect the removal capability of the treatment units.

Concentrations measured in the influent to the biological oxidation tank were usually lower than those in the influent to the WWTP. Therefore, some removal occurred in the units prior to the biological reactor. For instance, the storage tank is not equipped with mixers, and therefore some settlement of the suspended solids can take place. Adsorption to settled solids can be one of the reasons of the lower concentrations; furthermore, some transformations could have occurred to the drugs in wastewater within the different stages of the WWTP. Since the adopted analytical method measured only the origin compound, by-products or transformation products could not be detected.

In most cases, the biological oxidation process was capable of further reducing the amount of drugs in the liquid phase with a variable efficiency depending on the influent load. At same sampling times, however, it was observed a release of the previously adsorbed compound. Ranges of removal efficiency, calculated only when the effluent showed a lower concentration than in the influent, were found to be within the following ranges: 33-84\% (average $59.3 \%$ ) for AM, 33-97\% (average 62.6\%) for MET, 33$57 \%$ (average $43.8 \%$ ) for BEG and $29-83 \%$ (average $45.6 \%)$ for $\mathrm{THC}-\mathrm{COOH}$. The values determined for AM, MET and THC-COOH are in a good agreement with the data reported by other authors. For instance, HuertaFontela et al. (2008) refer 52-99 and 44-99\% removal efficiency of AM and MET, respectively. Different research groups indicate the following range of values: $52-99 \%$ for AM, $44-99 \%$ for MET, $83-100 \%$ for BEG and $11-99 \%$ for THC-COOH (Bijlsma et al. 2009; Loganathan et al. 2009; Zuccato and Castiglioni 2009).
Table 2 Main chemical-physical properties of the drugs

\begin{tabular}{|c|c|c|c|c|c|}
\hline Chemical & $\begin{array}{l}\text { Molecular weight } \\
(\mathrm{MW})[\mathrm{g} / \mathrm{mol}]\end{array}$ & $\gamma_{\text {sat }}[\mathrm{mg} / \mathrm{L}]$ & $H[\mathrm{~atm} \mathrm{~m} / \mathrm{mol}]$ & $\begin{array}{l}\log \\
K_{\mathrm{OC}}\end{array}$ & $\begin{array}{l}\log \\
K_{\mathrm{OW}}\end{array}$ \\
\hline Amphetamine & 135.21 & 20,800 (@25 ㄷ) & $1.08 \cdot 10^{-6}$ & 2.88 & 1.76 \\
\hline Methamphetamine & 149.23 & 13,290(@25 C) & $2.37 \cdot 10^{-6}$ & 2.88 & 2.95 \\
\hline 11-Nor- $\Delta$ 9-THC-9carboxy & 344.44 & $0.04284\left(@ 25^{\circ} \mathrm{C}\right)$ & $2.44 \cdot 10^{-7}$ & 5.50 & 7.60 \\
\hline Benzoylecgonine & 289.33 & $1065\left(@ 25{ }^{\circ} \mathrm{C}\right)$ & $1.03 \cdot 10^{-13}$ & 2.30 & 1.32 \\
\hline
\end{tabular}



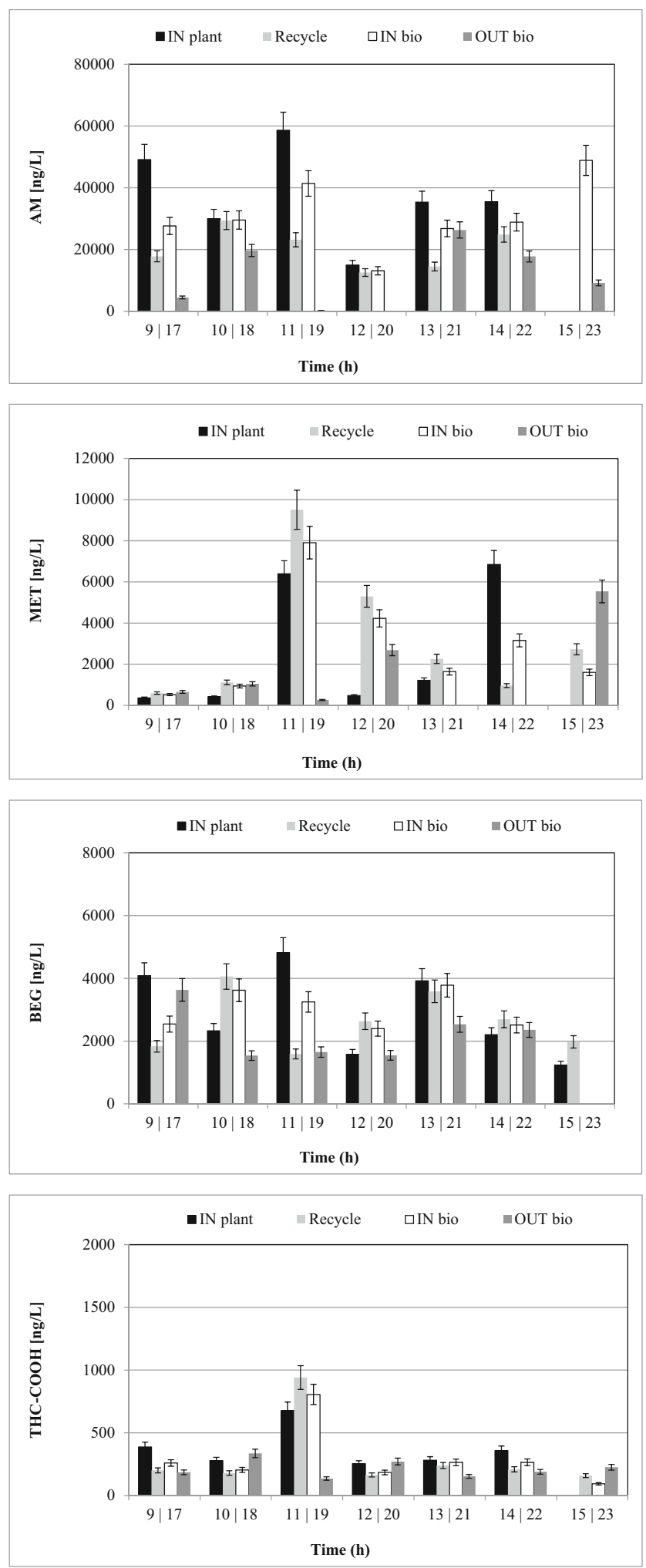

Fig. 2 Average concentrations of AM, MET, BEG and THC-COOH in the different sections of the WWTP

Postigo et al. (2010) reported that removal efficiency increased in the order of amphetamine-like compounds $<$ cannabinoids $<$ opioids $<$ cocainics.
In the case of BEG, removals determined in the present study were still in the range of data referred by literature, although the average was a bit lower. This can be explained by the fact that removal efficiency of wastewater treatment technologies depends not only on the concentration load and molecular nature of drugs and their metabolites but also on the specific operating conditions of the plant and on the composition of wastewater. There might have been wastewater components interfering with drug removal.

Owing to the incomplete removal, effluent of the WWTP still contained residual concentrations of all drugs. Relatively high concentrations were also found in the sludge recycle line. Although the higher removal rate, AM showed the greater concentration in the effluent due to the highest load entering the plant, while $\mathrm{THC}-\mathrm{COOH}$ the lowest one.

These results highlight the good capability of the WWTP to remove the selected drugs; however, as reported by several authors, drugs are only partially removed by the WWTP and the plant effluent still contains residual concentrations of all drugs, which then enter the receiving water body. Furthermore, they may also bound to sewage sludge solids which are then be applied to land in agricultural areas (Pal et al. 2013). Therefore, the WWTP needs to be upgraded with further treatment units specifically designed to enhance the overall removal of drugs.

All the investigated drugs showed a wide variability of concentration with time, both on a daily and weekly basis: this can be explained by the strict correlation between the load released into the sewage and the habits and types of consumers served by the sewage.

Lai et al. (2016) observed higher consumption of cocaine and MDMA in the large cities than in the rural towns. These two drugs also showed higher rates of use during weekends than weekdays. By contrast, methamphetamine use remained relatively steady throughout a week and was remarkably similar across study sites, except for a few large cities that had elevated use. Bodík et al. (2016) found that methamphetamine was the most commonly used illegal drug in all the regions of Slovakia monitored in their study. The highest 2year mean concentrations of THC-COOH, a cannabis biomarker, were measured in the sewage from two of the monitored cities to be 191 and $171 \mathrm{ng} / \mathrm{L}$, respectively. This data are in good agreement with the concentrations of THC-COOH measured in the present study.

The design of new physical-chemical units to enhance WWTP removal efficiency might be difficult due to this wide concentration variability of drug load entering the plant. Therefore, it would be worthwhile to investigate if performance of the biological process can be enhanced by properly modifying the operating parameters such as the mean cell residence time or the air flow rate. These modifications can be implemented by maintaining the same type of reactor. Alternatively, a different biological process might be considered, e.g. 
Membrane Biological Reactor or Attached Biomass Systems. Studies on these issues are highly recommended.

\section{Batch tests}

Figure 3 shows residual concentration of AM, MET, BEG and THC-COOH measured in the batch tests at the end of each contact time. Results obtained are reported and described below for each drug.

Concentrations lacking at any time in Fig. 3 are those that could not be determined with enough analytical reliability. Particularly, problems were encountered mainly in determination of BEG in batch tests.

\section{Amphetamine}

As far as AM is concerned, total percentage removal $(R(\%) 3)$ at the end of the test (i.e. $48 \mathrm{~h}$ ) was $52 \%$ as average of several replicates; therefore, there was still a significantly high concentration leftover (about $500 \mathrm{ng} / \mathrm{L}$ ). Removal throughout the test was mainly due to adsorption and biodegradation, while volatilization accounted for $22 \%$. This is in agreement with the Henry's constant value $\left(H=1.08 \cdot 10^{-6} \mathrm{~atm} \mathrm{~m}^{3} \mathrm{~mol}^{-1}\right)$ which indicates a moderate tendency of the compound to volatilize. Furthermore, AM is characterized by $\log K_{\mathrm{OC}}$ of 2.88 and $\log$ $K_{\text {OW }}$ of 1.76 (USEPA 2011), which highlight that the compound is less amenable to adsorption and bioconcentration in the sludge. Values of $\log K_{\mathrm{D}}$ and $\log K_{\mathrm{OM}}$ calculated at the end of the last contact time according to Eqs. (12) and (13), were found to be 3.07 and 3.19, respectively, i.e. slightly above data obtained through modelling (USEPA 2011). These properties can explain the high residual concentration in the liquid phase at the end of the test. It is likely that the compound was firstly uptaken from the liquid phase onto the sludge solids and then used by microorganisms for their metabolism; therefore, the biodegradation process might be kinetically limited by the low adsorption rate. During batch tests, COD and ammonia-nitrogen concentration were always monitored. It was observed a continuous decrease of COD since the beginning of the test, while nitrification started after $4 \mathrm{~h}$, as also confirmed by the decreasing pattern of $\mathrm{pH}$. Dissolved oxygen concentration remained at about $4 \mathrm{mg} / \mathrm{L}$ in the first $8 \mathrm{~h}$ of the test and then increased up to about $7 \mathrm{mg} / \mathrm{L}$. It is well-known that activity of nitrifying bacteria can be kinetically limited by high COD concentrations: this might explain the delay in the beginning of nitrification.

Measurements of DO during Experiments 1 and 2 showed negligible variations throughout the tests, thus confirming the absence of biological activity in these tests. For instance, in the Blank test DO was always above $8 \mathrm{mg} / \mathrm{L}$, whereas in the Inactivated sludge test it maintained a value above $7 \mathrm{mg} / \mathrm{L}$. The presence of nutrients and sludge solids in the latter test was likely responsible of the lower solubility of DO in the liquor.
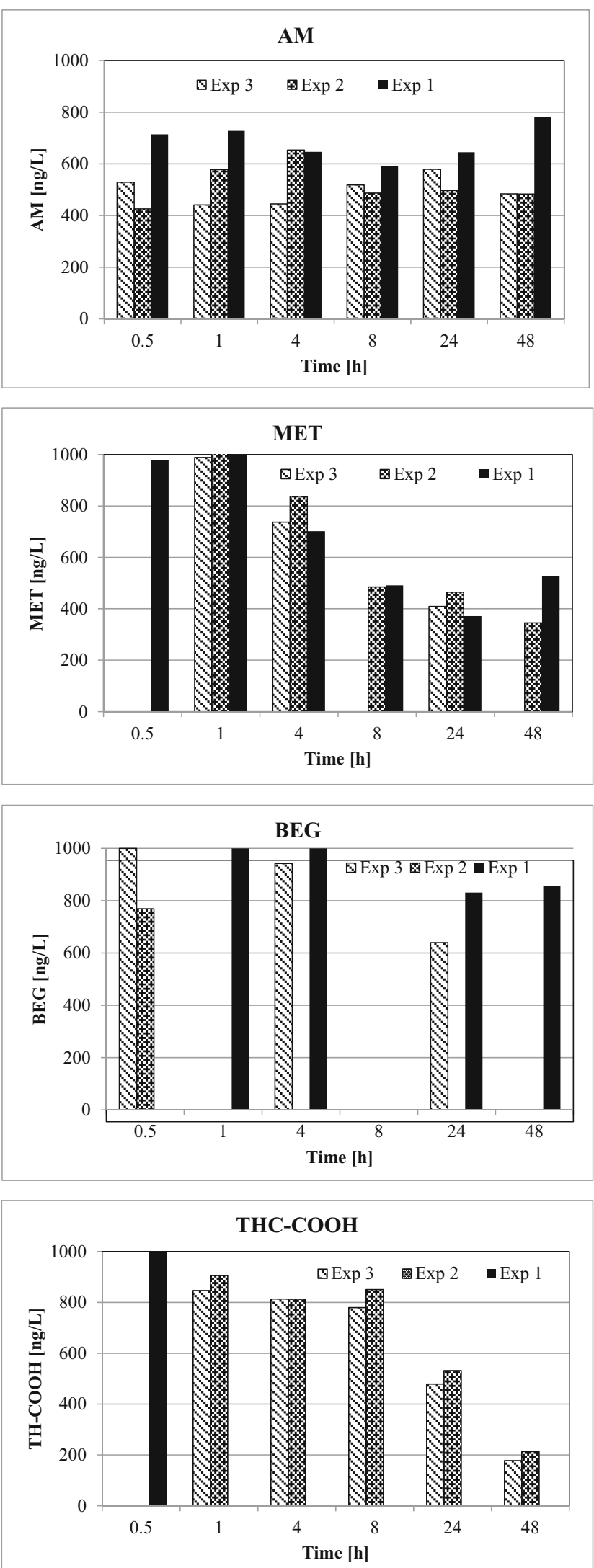

Fig. 3 Time-profile of residual concentrations of AM, MET, BEG and THC-COOH in Experiments 1, 2 and 3 
The best fitting of the experimental data from Experiment 3 was achieved by the pseudo-second order model; the average value of the rate constant, $K_{2}{ }^{\prime}$, was found to be equal to 0.011 $1 / \mathrm{h}$.

The efficiency measured in the batch test did not differ much from the value found in the full-scale (i.e. 59\%). It is noteworthy that in the latter case the influent concentration to the biological reactor was always much higher than in the feed to the batch test where, by contrast, the contact time was longer. These data seem to indicate that higher concentrations of AM do not significantly inhibit biomass activity; furthermore, extending the residence time in the reactor is useless since the trend of concentration towards the end of the $48 \mathrm{~h}$ batch test seems to have reached a pseudo-stationary value.

Removal in both full-scale reactor and batch tests was always incomplete, leaving a significant AM concentration in the effluent.

\section{Methamphetamine}

A decrease of MET concentration was observed starting only after $1 \mathrm{~h}$ of contact time. A similar pattern was reported for COD and ammonia oxidation. This initial lag phase in the biological activity is likely to be due to the low oxygen availability recorded in the first hour of the test. Afterwards, oxygen was observed to rise to $4-5 \mathrm{mg} / \mathrm{L}$ and remained within this range up to 24 contact time; then, it increased to above $6 \mathrm{mg} /$ L. Both COD and ammonia oxidation took place continuously until the end of the batch test. By contrast, MET removal seems to have reached stationary conditions at $t=24 \mathrm{~h}$, with no further decrease observed afterwards. Efficiency determined at this contact time in Experiment 3 was 59\%, which is very close to the value observed at full-scale (where it was $62.6 \%$ as average).

Values of $\log K_{\mathrm{OC}}$ and of $\log K_{\mathrm{OW}}$, determined through modelling (USEPA 2011), were found to be 2.88 and 2.95, respectively, indicating a low tendency to adsorption (similarly to AM) and a moderate capacity to bioconcentration. Values of $\log K_{\mathrm{D}}$ and $\log K_{\mathrm{OM}}$, calculated at the end of the last contact time (i.e. $t=48 \mathrm{~h}$ ), by following Eqs. (12) and (13), were found to be 2.25 and 2.34, respectively. Measurements of DO in Experiments 1 and 2 showed similar trends as observed in the batch tests with AM: for instance, the values did not change appreciably and remained above 9 and $8 \mathrm{mg} / \mathrm{L}$, respectively, throughout the tests. Both MET and AM drugs do not seem to negatively affect COD and ammonia oxidation processes when present at the concentration applied to the batch tests.

Best fitting of data from Experiment 3 was obtained by the pseudo-second-order kinetic model; the rate constant, $K_{2}{ }^{\prime}$, was found to be $0.00291 / \mathrm{h}$.

The results obtained at full-scale and in the batch tests highlight that a conventional WWTP is capable of only a partial removal of MET, similarly to AM. However, slightly better performance seems to be achievable with MET than with AM.

\section{Benzoylecgonine}

Time trends of BEG in Experiments 1,2 and 3 were affected by a high analytical variability. Total removal measured in Experiment 3 at $t=24 \mathrm{~h}$ was about $36 \%$, which is a bit lower than the value observed at full-scale (where it was $43.8 \%$ ). This might be due to the lower concentration in the feed to the batch test as compared to the average influent to the plant.

Looking at the data of Experiment 1, removal due to volatilization accounted for $17 \%$ at $24 \mathrm{~h}$. Data about adsorption were not enough reliable. There might be also some chemical transformation of BEG due to e.g. hydrolysis which influenced BEG reduction. Both adsorption and bioconcentration contributions were likely to be low, based on the values of log $K_{\mathrm{OC}}$ and $\log K_{\mathrm{OW}}(2.30$ and 1.32 , respectively) found through modelling (USEPA 2011). Values of $\log K_{\mathrm{D}}$ and $\log K_{\mathrm{OM}}$, experimentally calculated at $t=24 \mathrm{~h}$ through Eqs. (12) and (13), were found to be 1.96 and 2.08 , respectively. The few kinetic data obtained in the batch tests did not allow to calculate the best fitting model.

COD removal and nitrification proceeded continuously throughout Experiment 3. Therefore, BEG does not seem to affect biological activity. This was also confirmed by oxygen concentration registered in Experiment 3: the values always remained close to $4 \mathrm{mg} / \mathrm{L}$. By contrast, DO in Experiments 1 and 2 assumed values above 9 and $8 \mathrm{mg} / \mathrm{L}$ throughout the tests, respectively, indicating absence of consumption through biological activity.

Results obtained through batch tests and the limited removal observed at the full-scale suggest that BEG cannot be removed to a large extent in a conventional WWTP: further advanced treatment processes must be implemented to this purpose.

\section{$\mathrm{THC}-\mathrm{COOH}$}

Total removal observed at the end of Experiment 3 (i.e. $t=48 \mathrm{~h}$ ) was $82 \%$. The value is in the range of efficiency measured at full-scale: in particular, when the influent concentration to the plant was similar (at time 11/19, it was $805 \mathrm{ng} / \mathrm{L}$ ), the efficiency was close to that measured in the batch tests (i.e. 83 and $82 \%$, respectively).

Concentrations measured after $t=0.5 \mathrm{~h}$ were too low to be due only to volatilisation: it is likely that THC-COOH was subjected to chemical transformations beside volatilization when it was alone in the solution (Experiment 1). Due to a lack of a clear explanation, these data were not reported in Fig. 3. 
Because of the incomplete removal, there was a residual concentration leftover in the liquid phase at the end of the test. However, removal was higher than the average measured for the other drugs. It was due to a combination of mainly adsorption and biodegradation. The high values of $\log K_{\mathrm{OC}}$ and $\log K_{\mathrm{OW}}$ (5.51 and 7.60, respectively) (USEPA 2011) are in agreement with these results, as well as the low volatilization confirmed by the Henry's constant value being $2.44 \cdot 10^{-7} \mathrm{~atm} \mathrm{~m}^{3} \mathrm{~mol}^{-1}$. Particularly, the high value of the octanol/water partition coefficient of the cannabinoids such as THC-COOH reflects their high hydrophobicity; therefore, they can be found bound to sewage sludge. The values of $\log K_{\mathrm{D}}$ and $\log K_{\mathrm{OM}}$ calculated according to Eqs. (12) and (13) were found to be lower than expected, i.e. 2.34 and 2.45 , respectively.

COD removal and nitrification took place continuously since the beginning of the test and up to the end. This confirms that the high level of THC-COOH did not alter the efficiency of the biological process. The best fitting model of the kinetic data of Experiment 3 was found to be the order of one, with the kinetic constant equal to $0.032 \mathrm{1} / \mathrm{h}$. Based on the results of both full-scale and batch tests, it can be assessed that THC$\mathrm{COOH}$ is removed to a large extent in the oxidation tank of a conventional WWTP, without affecting the biological removal of the other contaminants. However, removal is incomplete as observed with AM, MET and BEG, although initial concentration of THC-COOH was much lower.

\section{Conclusions}

The present study focused on the presence and removal efficiency of amphetamine, methamphetamine, 11-nor- $\Delta 9$-THC9 carboxy and benzoylecgonine in the activated sludge tank of a WWTP for domestic sewage. Some analytical problems were encountered in the determination of the drugs in wastewater, due to the complex composition of the liquid matrix. Further studies are required to improve the method, with the aim also to provide a low time-consuming tool for measuring both sludge and liquid samples.

Among the drugs, AM was found as the most abundant in the influent with values far above those reported by the specialized literature; by contrast, THC-COOH was present at the lowest concentration. Content of all drugs was reduced in the treatment stages prior to the oxidation tank, likely for adsorption onto settled solids. Nonetheless, main reduction occurred in the biological reactor. Taking into account results from both full-scale observations and batch tests, removals in the biological reactor were found in the following ranges: $33-84 \%$ for AM, 33-97\% for MET, 33-57\% for BEG and 29-83\% for THC-COOH. These removals were due to a combination of mainly adsorption and biodegradation, while volatilization did not play a significant role. Drugs were likely to be subjected also to different transformation processes, e.g. hydrolysis.

\section{References}

APHA, AWWA, WEF (2005) Standard methods for the examination of water and wastewater, 21st edn, Washington DC

Bijlsma L, Sancho JV, Pitarch E, Ibáñez M, Hernádez F (2009) Simultaneous ultra-high-pressure liquid chromatography-tandem mass spectrometry determination of amphetamine-like stimulants, cocaine and its metabolites, and a cannabis metabolite in surface water and urban wastewater. J Chromatogr A 1216:3078-3089

Bodík I, Mackul'ak T, Fáberová M, Ivanová L (2016) Occurrence of illicit drugs and selected pharmaceuticals in Slovak municipal wastewater. Environ Sci Pollut Res 23:21098-21105

Boles TM, Wells MJM (2010) Analysis of amphetamine and methamphetamine as emerging pollutants in wastewater and wastewaterimpacted streams. J Chromatogr A 1217(16):2561-2568

Castiglioni S, Zuccato E, Chiabrando C, Fanelli R, Bagnati R (2006) Identification and measurement of illicit drugs and their metabolites in urban wastewater by liquid chromatography-tandem mass spectrometry. Anal Chem 78:8421-8429

Chiaia AC, Banta-Green C, Field J (2008) Eliminating solid phase extraction with large volume injection LC/MS/MS: analysis of illicit and legal drugs and human urine indicators in US wastewaters. Environ Sci Technol 42:8841-8848

Chiavola A, Tedesco P, Boni MR (2016) Fate of some endocrine disruptors in batch experiments using activated and inactivated sludge. Water Air Soil Pollut 227:424

Clara M, Strenn B, Saracevis E, Kreuzinger N (2004) Adsorption of bisphenol-A, $17 \beta$-estradiol and $17 \alpha$-ethinylestradiol to sewage sludge. Chemosphere 56:843-851

Collivignarelli C, Bertanza G, Bina S (1995) La verifica idrodinamica nel trattamento delle acque. Basi teoriche. Procedure di applicazione. Esempi. Collana Ambiente, vol. 8. CIPA Editore, Italy (in Italian)

Daughton CG (2011) Illicit drugs: contaminants in the environment and utility in forensic epidemiology. In: Reviews of Environmental Contamination and Toxicology 210, Springer Science+Business Media, LLC 2011

Díaz-Cruz MS, García-Galán MJ, Guerra P, Jelic A, Postigo C, Eljarrat E, Farré M, López de Alda MJ, Petrovic M, Barceló D (2009) Analysis of selected emerging contaminants in sewage sludge. Trends Anal Chem 28(11):1263

Evgenidou EN, Konstantinou IK, Lambropoulou DA (2015) Occurrence and removal of transformation products of PPCPs and illicit drugs in wastewaters: a review. Sci Total Environ 505:925-926

Hall W, Degenhardt L, Sindicich N (2008) In: Heggenhougen K, Quah S (eds) Illicit drug use and the burden of disease. International encyclopedia of public health, Elsevier, pp 523-530

Huerta-Fontela M, Galceran MT, Martin-Alonso J, Ventura F (2008) Occurrence of psychoactive stimulatory drugs in wastewaters in north-eastern Spain. Sci Total Environ 397:31-40

Kaleta A, Ferdig M, Buchberger W (2006) Semiquantitative determination of residues of amphetamine in sewage sludge samples. J Sep Sci 29:1662-1666

Kasprzyk-Hordern B, Dinsdale RM, Guwy AJ (2009) The removal of pharmaceuticals, personal care products, endocrine disruptors and illicit drugs during wastewater treatment and its impact on the quality of receiving waters. Water Res 43:363-380

Kasprzyk-Hordern B, Kondakal VVR, Baker DR (2010) Enantiomeric analysis of drugs of abuse by chiral liquid chromatography coupled with tandem mass spectrometry. J Chromatogr A 1217:4575-4586

Lai FY, O’Brien J, Bruno R, Hall W, Prichard J, Kirkbride P, Gartner C, Thai P, Carter S, Lloydh B, Burns L, Mueller J (2016) Spatial variations in the consumption of illicit stimulant drugs across Australia: a nationwide application of wastewater-based epidemiology. Sci Total Environ 568:810-818 
Loganathan B, Phillips M, Mowery H, Jones-Lepp TL (2009) Contamination profiles and mass loadings of macrolide antibiotics and illicit drugs from a small urban wastewater treatment plant. Chemosphere 75:70-77

Loos R, Carvalho R, António DC, Comero S, Locoro G, Tavazzi S, Paracchini B, Ghiani M, Lettieri T, Blaha L, Jarosova B, Voorspoels S, Servaes K, Haglund P, Fick J, Lindberg RH, Schwesig D, Gawlik BM (2013) EU-wide monitoring survey on emerging polar organic contaminants in wastewater treatment plant effluents. Water Res 47:6475

Pal R, Megharaj M, Kirkbride KP, Naidu R (2013) Illicit drugs and the environment - a review. Sci Total Environ 463-464:10791082

Pomati F, Orlandi C, Clerici M, Luciani F, Zuccato E (2008) Effects and interactions in an environmentally relevant mixture of pharmaceuticals. Toxicol Sci 102:129

Postigo C, de Alda MJL, Barceló D (2010) Drugs of abuse and their metabolites in the Ebro River basin: occurrence in sewage and surface water, sewage treatment plants removal efficiency, and collective drug usage estimation. Environ Int 36(1):75-84

Saito T, Mase H, Takeich S, Inokuchi S (2007) Rapid simultaneous determination of ephedrines, amphetamines, cocaine, cocaine metabolites, and opiates in human urine by GC/MS. J Pharm Biomed Anal 43:358-363

Taewoo Y, Willie FH Jr (2007) The effect of biomass characteristics on partitioning and sorption hysteresis of $17 \alpha$-ethinylestradiol. Water Res 41:1543-1553

USEPA (2011) Estimation program Interface Suite ${ }^{\mathrm{TM}}$ for Microsoft ®Windows, v. 4.10. United States Environmental Protection Agency, Washington DC

van Nuijs ALN, Castiglioni S, Tarcomnicu I, Postigo C, de Alda ML, Neels H, Zuccato E, Barceló D, Covaci A (2011) Illicit drug consumption estimations derived from wastewater analysis: a critical review. Sci Total Environ 409:3564-3577

van Nujis ALN, Tarcomincu I, Bervoets L, Blust R, Jorens PG, Neels H, Covaci A (2009a) Analysis of drugs of abuse in wastewater by hydrophilic interaction liquid chromatography-tandem mass spectrometry. Anal Bioanal Chem 395:819-828

van Nujis ALN, Pecceu B, Theunis L, Dubois N, Charlier C, Jorens PG, Bervoets L, Blust R, Meulemans H, Neels H, Covaci A (2009b) Can cocaine use be evaluated through analysis of wastewater? A nationwide approach conducted in Belgium. Addiction 104:734-741

Zuccato E, Castiglioni S (2009) Illicit drugs in the environment. Phil Trans R Soc A 367:3965-3978 